\title{
ANALYSIS OF FREE VIBRATIONS OF CANTILEVER BARS WITH PARABOLICALLY VARIABLE CROSS-SECTIONS USING THE RAYLEIGH'S METHOD
}

\author{
Olga Szlachetka ${ }^{\bowtie}$, Jacek Jaworski, Marek Chalecki \\ Faculty of Civil and Environmental Engineering, Warsaw University of Life Sciences - SGGW, Warsaw
}

\begin{abstract}
The Rayleigh's method can be used to determine the first natural frequency of bars (beams or posts) with non-uniform cross-section. The authors have analysed slender bars made of an elastic material and having the shape of a solid of revolution: a curvilinear truncated cone and curvilinear conical pipe. It has been assumed that the bar axis deflected during vibrations has a shape of a beam deflected by a static constant continuous load. The Rayleigh's method has been applied in the paper in aim to determine the first frequency of free (transverse) vibrations of posts formed as a cantilever bars having the shape of solid and hollow curvilinear truncated cone with the generatrix being a parabola which is convex in relation to the cone axis. The results of calculations are very close to those obtained with finite element method (FEM).
\end{abstract}

Key words: cantilever bar, non-uniform section, first natural frequency, Rayleigh's method

\section{INTRODUCTION}

Bar elements with non-uniform cross-sections are quite commonly applied in building construction for they allow more efficient use of their cross-sections and reduction of their mass. In aim to define a mode and frequency of free vibrations of such elements, various methods are used; one of them is an integration of the differential equation of Bernoulli-Euler's beam. Various boundary conditions are assumed, corresponding to various static schemes of the bar. Such benchmark solution for a wedge bar and truncated cone bar was obtained by Conway and Dubil (1965) in the form of Bessel functions, replaced for the numerical calculations by polynomial equivalents. The truncated cone bar problem was also analysed by Naguleswaran (1994) using the Frobenius method, Coşkun, Atay and Öztürk (2011) using analytical approximate techniques, and Abdelghany, Ewis, Mahmoud and Nassar (2015) using a differential transformation method.

A number of investigations concerned bars with rectangular cross-section where one of the cross-section dimensions is constant and the second one changes linearly (Datta \& Sil, 1996), exponententially (Ece, Aydogdu $\&$ Taskin, 2007) or parabolically (Caruntu, 2007). Zhou and Cheung (2000) used the Rayleigh-Ritz method for double tapered parabolic beams. Caruntu (2009) provided the solution for free vibrations of a spindle-shaped cantilever bar - a curvilinear solid of revolution with variable circular cross-section, sharp free end and generatrices having the shape of parabola being convex in relation to the longitudinal axis of the solid.

It is very hard task, however, to obtain similar solutions for non-prismatic bars having the shape of conical pipes (solids of revolution with the recti- or curvilinear generatrices of the internal and external cone).

$凶_{\text {olga_szlachetka@sggw.pl }}$ 
Papers concerning hollow truncated cones - solids of revolution with recti- or curvilinear generatrices (Kang \& Leissa, 2004; Wu \& Chiang, 2004) are rare and their authors deal only with selected, special geometrical cases of hollow bars.

For many cantilever constructions, such as towers, posts, or chimneys, the construction susceptibility to dynamic influences of wind gusts has to be checked. It is needed here to know an approximated value of the first natural frequency of transverse vibrations. Jaworski and Szlachetka (2017) provide examples of such calculations using the Rayleigh's method for the constructions having the form of solid and hollow bodies of revolution with variable circular cross-section and generatrices having the shape of parabola being concave in relation to the cone longitudinal axis.

The topic of this paper is to determine - using the Rayleigh's method - the first frequency of free vibrations of non-prismatic (solid and hollow) cantilever bars with the generatrices having the shape of parabola being convex with relation to the bar axis. Hereinafter, such shape will be described as a solid conical barrel and hollow conical barrel. Moreover, it has been proved in the paper that a similar approach is effective for hollow solids of revolution with other shapes - such ones whose external generatrix is a convex parabola.

It has been assumed that the vibration amplitude is small, the material is homogeneous, isotropic and ideally elastic, the bars are slender, their mass is distributed continuously. The Mathematica environment has been used in the calculations. The obtained results have been compared to those obtained using finite element method - FEM (in ANSYS). The obtained vibration periods have been compared to those ones for truncated solid cone and conical pipe, both with rectilinear generatrices.

\section{MATERIAL AND METHODS}

\section{Solid conical barrel cantilever bar}

Consider a cantilever bar with the shape of a curvilinear solid truncated cone whose generatrices are the parabolas described with formula (2); this formula is a dependence of a bar diameter in any cross-section on a coordinate $x$ of localization of this cross-section. It has been assumed that the neutral axis deflected during the first mode of (transversal) natural vibrations has a shape of a bar deflected by a uniform continuous load $q$ (Fig. 1). A denotation has been introduced

$$
\eta=\frac{D}{d}
$$

where: $\eta$ - quotient of the diameters describing a convergence ratio of external walls of the solid;

$D$ - bar diameter at the clamp;

$d$ - bar diameter at the free end.

Provided that $d>0$ and $d<D$, then $\eta \neq 1$

$$
\begin{gathered}
\Delta(x)=D-(D-d) \frac{x^{2}}{L^{2}}=D a\left(a^{-1}-x^{2}\right) \\
a=\frac{\eta-1}{\eta L^{2}}
\end{gathered}
$$




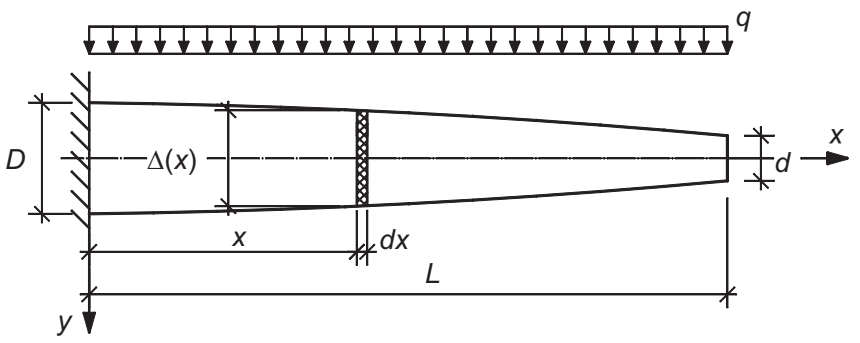

Fig. 1. Curvilinear solid truncated cone cantilever bar with the generatrix being a convex parabola (solid cone barrel), uniformly loaded

The second area moment of the bar cross-section is expressed by formula (4)

$$
J(x)=\frac{\pi \Delta^{4}(x)}{64}=\frac{\pi D^{4} a^{4}}{64}\left(a^{-1}-x^{2}\right)^{4}
$$

The deflection has been calculated by the integration of the differential equation of bar elastic deflection curve

$$
E J(x) \frac{d^{2} u(x)}{d x^{2}}=-M(x)=\frac{q}{2}\left(x^{2}-2 L x+L^{2}\right)
$$

where: $E$ - longitudinal modulus of elasticity;

$u(x)$ - deflection;

$M(x)$ - bending moment in the bar section given by a coordinate $x$;

$q$ - uniform continuous load;

$L-$ bar length.

Equation (5) has been integrated twice and the bar deflection curve has been obtained as

$$
u(x)=\frac{32 q}{\pi E D^{4} a^{4}} P(x)
$$

where

$$
\begin{aligned}
& P(x)=C_{1} x+C_{2}+\frac{A^{2}+L^{2}-2 L x}{24 A^{2}\left(A^{2}-x^{2}\right)^{2}}+\frac{5 L^{2}-A^{2}-6 L x}{48 A^{4}\left(A^{2}-x^{2}\right)}+ \\
& -\frac{5 L^{2}-A^{2}}{16 A^{6}}+\frac{\left(5 L^{2}-A^{2}\right) x-2 A^{2} L}{32 A^{7}} \ln \left(\frac{A+x}{A-x}\right)
\end{aligned}
$$

wherein integration constants $C_{1}$ and $C_{2}$ are equal to, respectively

$$
C_{1}=\frac{L}{3 A^{6}} ; \quad C_{2}=\frac{2 L^{2}-A^{2}}{12 A^{6}}
$$

and the parameter, appearing in formulas (7) and (8), is described by the formula

$$
A=\sqrt{\frac{1}{a}}=\sqrt{\frac{\eta L^{2}}{\eta-1}}
$$


Assuming that the neutral bar axis deflected during vibrations has a shape described by formula (6), the potential energy in a deflected position and the kinetic energy in the position of equilibrium have been calculated. The potential energy is equal to

$$
E_{p}=\int_{0}^{L} \frac{1}{2} q u(x) d x=\frac{1}{2} \frac{32 q^{2}}{\pi E D^{4} a^{4}} \int_{0}^{L} P(x) d x
$$

If the mass of a material slice with a thickness $d x$ is denoted as $m(x)$, i.e.

$$
d m(x)=\frac{\rho \pi}{4} D^{2}(x) d x=\frac{\rho \pi}{4} D^{2} a^{2}\left(A^{2}-x^{2}\right)^{2} d x
$$

where $\rho$-mass density;

then the kinetic energy of the bar is determined as

$$
E_{k}=\int_{0}^{L} \frac{1}{2} d m(x) \omega^{2} u^{2}(x)=\frac{1}{2} \frac{\rho \pi}{4} D^{2} a^{2} \omega^{2}\left(\frac{32 q}{\pi E D^{4} a^{4}}\right)^{2} \int_{0}^{L}\left(A^{2}-x^{2}\right)^{2} P^{2}(x) d x
$$

The energy comparison enables to determine the frequency. The period $T$ is equal to

$$
T=\frac{2 \pi}{\omega}=\frac{4 \pi}{D a} \sqrt{\frac{2 \rho}{E}} \sqrt{\frac{\int_{0}^{L}\left(A^{2}-x^{2}\right)^{2} P^{2}(x) d x}{\int_{0}^{L} P(x) d x}}
$$

where $\omega$-vibration frequency.

\section{Hollow conical barrel cantilever bar}

Figure 2 presents a solid of revolution (curvilinear conical pipe) where the generatrices of the internal and external walls are convex parabolas. The external and internal diameters in a bar cross-section defined by a coordinate $x$ are described by formulas (2) and (14), respectively. It has been assumed that: $0<d_{0}<d, \mu \neq 1$.

$$
\delta(x)=D_{0}-\left(D_{0}-d_{0}\right) \frac{x^{2}}{L^{2}}=D_{0} b\left(b^{-1}-x^{2}\right)
$$

where

$$
\begin{gathered}
\mu=\frac{D_{0}}{d_{0}} \\
b=\frac{\mu-1}{\mu L^{2}}
\end{gathered}
$$

The denotations in Figure 2 and in the subsequent formulas are:

$D$ and $d$ are bigger and smaller external diameter of the bar;

$D_{0}$ and $d_{0}$ are bigger and smaller internal diameter of the bar. 


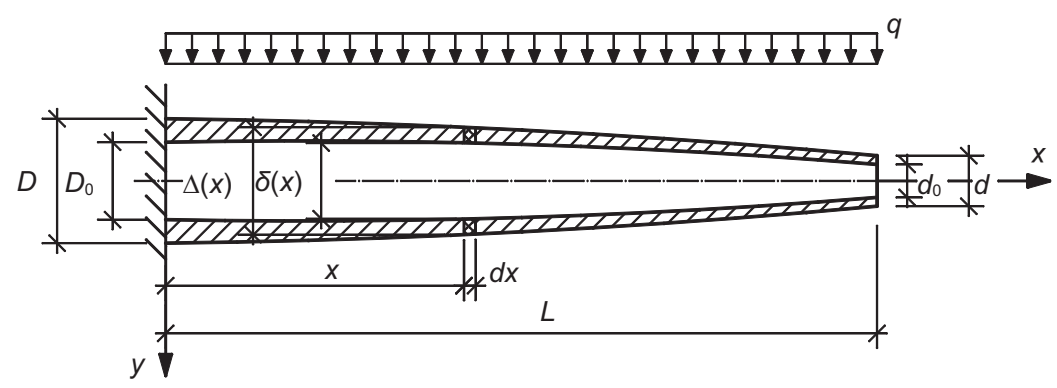

Fig. 2. Curvilinear conical pipe cantilever bar with the generatrices being convex parabolas (hollow cone barrel), uniformly loaded

The second area moment of the bar cross-section is described by the formula

$$
J(x)=\frac{\pi \Delta^{4}(x)}{64}-\frac{\pi \delta^{4}(x)}{64}=\frac{\pi D^{4}}{64}\left[a^{4}\left(A^{2}-x^{2}\right)^{4}-\alpha^{4} b^{4}\left(B^{2}-x^{2}\right)^{4}\right]
$$

where

$$
\begin{gathered}
\alpha=\frac{D_{0}}{D} \\
B=\sqrt{\frac{1}{b}}=\sqrt{\frac{\mu L^{2}}{\mu-1}}
\end{gathered}
$$

Double integration of the differential equation of bar elastic deflection curve in the formula (5), with assumption of the second area moment described by formula (17), yields the bar deflection in the form

$$
u(x)=\frac{32 q}{\pi E D^{4}} R(x)
$$

The authors obtained a symbolic form of the expression $R(x)$ in the Mathematica environment, however it is too spacious to place it here.

The comparison of the expressions for the potential and kinetic energies allows to determine the vibration period

$$
T=\frac{2 \pi}{\omega}=\frac{4 \pi}{D} \sqrt{\frac{2 \rho}{E}} \sqrt{\frac{\int_{0}^{L}\left[a^{2}\left(A^{2}-x^{2}\right)^{2}-\alpha^{2} b^{2}\left(B^{2}-x^{2}\right)^{2}\right] R^{2}(x) d x}{\int_{0}^{L} R(x) d x}}
$$

Due to the size of these equations and to the necessity of numerical integration, it is the best to perform the calculations using a computer software - both for the solid and for the hollow cone barrel. 
Szlachetka, O., Jaworski, J., Chalecki, M. (2017). Analysis of free vibrations of cantilever bars with parabolically variable cross-sections using the Rayleigh's method. Acta Sci. Pol. Architectura, 16 (4), 5-14. doi: 10.22630/ASPA.2017.16.4.01.

\section{COMPUTATIONAL EXAMPLES, ACCURACY AND COMPARISON OF RESULTS}

The results obtained using the Rayleigh's method (Jaworski \& Szlachetka, 2017) have been compared to the exact results for the truncated cone bar with five different convergence ratios for external walls; these results are published (Lau, 1984) and were obtained in the form of Bessel functions, replaced by polynomial equivalents - as in the paper by Conway and Dubil (1965). The values obtained using Rayleigh's method are lower than those calculated by Lau - by $0.4 \%$ in average and the highest difference did not exceed $1 \%$ (Jaworski \& Szlachetka, 2017 ) - whereas the vibration period calculated by the authors in FEM was $0.2 \%$ higher in average than in the aforementioned paper. Such accuracy can be acknowledged as absolutely sufficient for engineering calculations. As the authors did not find in the literature any exact solutions for hollow curvilinear tapered cones, the results obtained for the three examples have been compared to those obtained from FEM (ANSYS).

The shapes of the parabolic generatrices of the hollow curvilinear cones were approximated in FEM calculations by 16 linear sections. Then, a regular HEXA mesh was created with application of SOLID elements. As the post altitude has been divided into 192 elements (12 on each section), the post wall thickness (relatively small) into 4 elements and the circumference into 40 elements (every 9 grades), it resulted in using about 30,000 elements.

Example 1. Figure 3 presents a comparison of the period calculated from formula (13), corresponding to the first frequency of (transversal) natural vibrations for a solid truncated cone steel post with the generatrix having the shape of convex parabola (solid conical barrel post), with the vibration periods of a solid truncated cone post. The results from Jaworski, Szlachetka and Aguilera-Cortés (2015) have been used. The following data have been assumed: $E=205 \mathrm{GPa}, \rho=7,850 \mathrm{~kg} \cdot \mathrm{m}^{-3}$, the post height $L=6 \mathrm{~m}$, the post diameter by the base $D=0.2 \mathrm{~m}$. Various ratios of inclination of lateral faces have been considered what corresponds to various diameters by the post head. The results have been compared to those obtained in FEM (ANSYS). The slenderness of those posts is considerable $(\lambda=L / D=30)$, hence a very good concordance of results occurs.

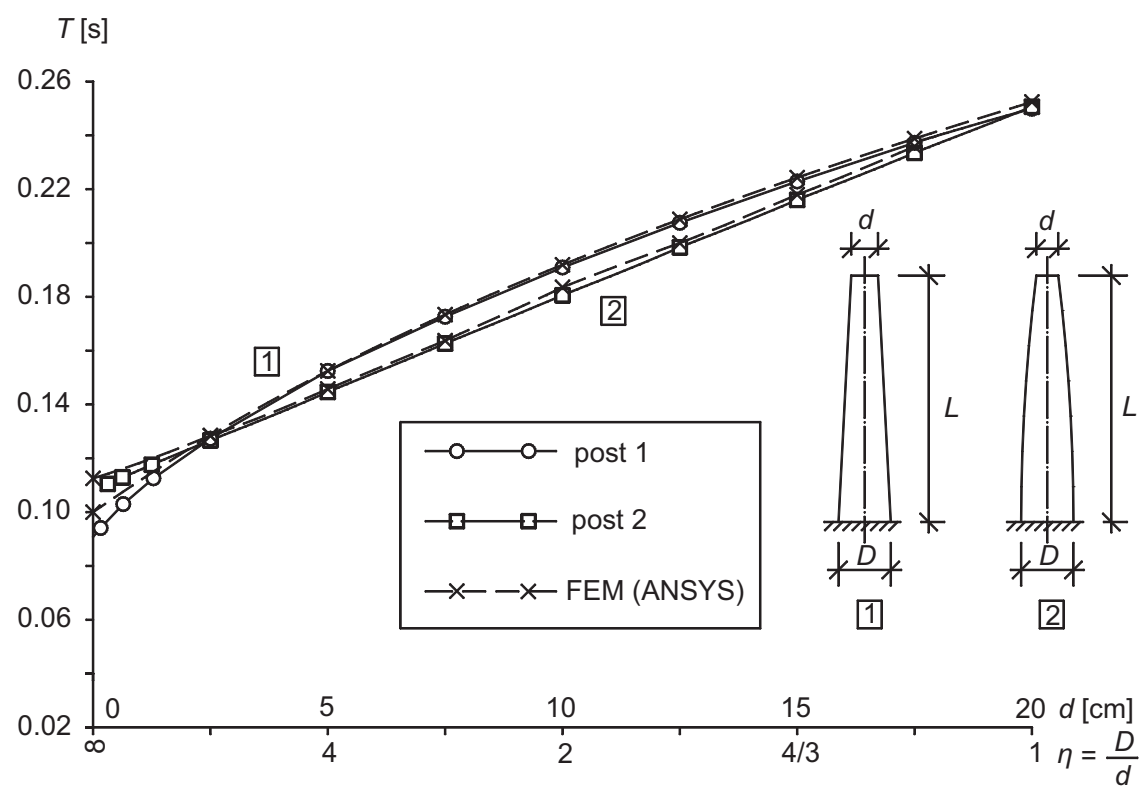

Fig. 3. Comparison of the vibration period $T$ of solid truncated cone steel posts with linear and parabolic generatrices 
As it was proven (Jaworski et al., 2015), the accuracy of results for the posts having almost conical shape (for the diameter $d$ close to 0 ) can be improved if one assumes in calculations that the bar axis deflected during vibrations has a shape of a beam deflected by a static continuous load proportional to the bar diameter.

Example 2. The comparison of vibration period for two ferroconcrete chimneys is presented in Figure 4. The generatrices for the first chimney are rectilinear. The generatrices of the internal and external sidewalls for the second one have the shape of convex parabola and the calculations have been performed according formula (21). The following data have been assumed: $\sqrt{\rho / E}=3.5 \cdot 10^{-4} \mathrm{~s} \cdot \mathrm{m}^{-1}$, the height $L=32 \mathrm{~m}$, the diameter by the base $D=4 \mathrm{~m}$, the wall thickness (horizontally measured) by the base $0.24 \mathrm{~m}$ and by the head $0.12 \mathrm{~m}$. Various convergence ratios of the external walls correspond to various external diameters in the head (d), varying from 3.5 to $0.5 \mathrm{~m}$. The results have been compared to those obtained in FEM.

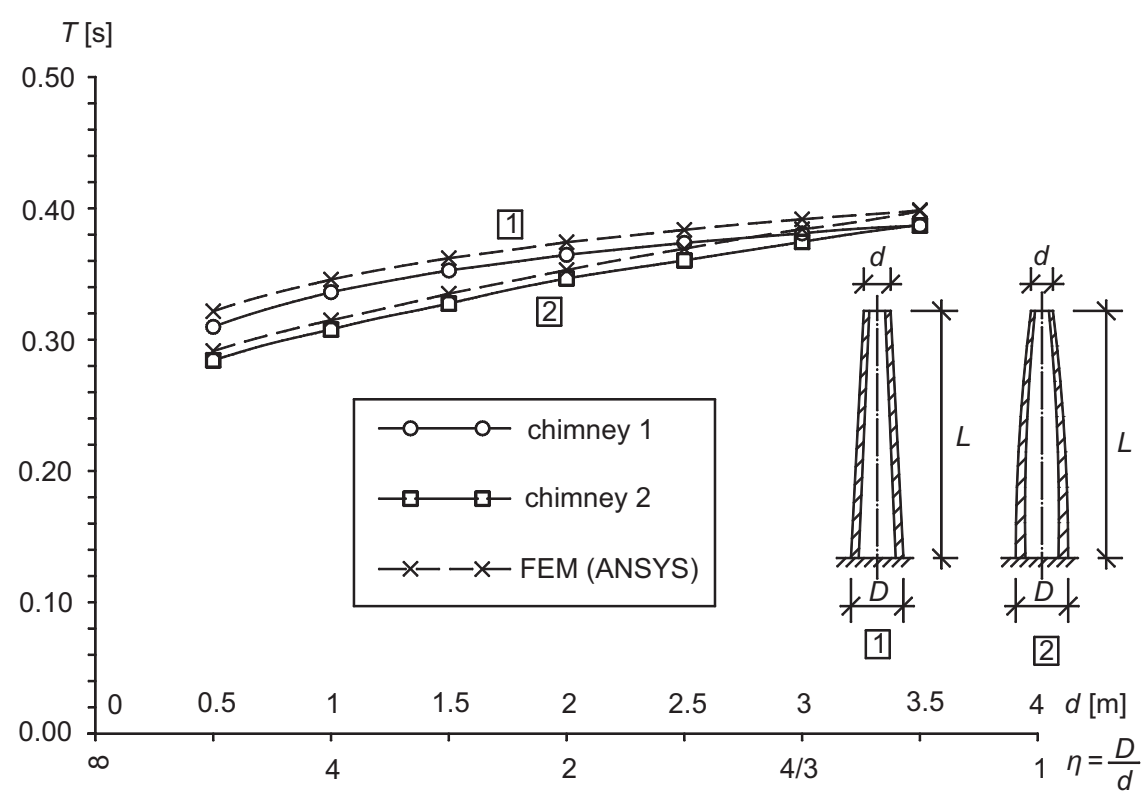

Fig. 4. Comparison of vibration period $T$ of ferroconcrete conical chimneys with rectilinear and parabolic generatrices

The slenderness of the chimneys is much lower than this of the posts in the previous example $(\lambda=L / D=8)$, hence the results of the calculations differ in more significant way from the results obtained in FEM - in average ca. 2.6\%. The ordinate of Curve 2 in Figure 4 (for the hollow conical barrel) for $\eta=2$ is determined from the interpolation due to the fact that formula (21) is not valid for $D_{0} / D=d_{0} / d$. For this particular case as well as for the case of a tube $\left(D=d, D_{0}=d_{0}\right)$ and cone $\left(d=0, d_{0}=0\right)$ appropriate formulas for vibration periods can be derived as it was done for a conical pipe (Jaworski \& Szlachetka, 2015). The results for the conical tube chimney have been taken from the aforementioned paper.

Example 3. In aim to present the wide spectrum of possible applications of the method having been used, it has been applied in this example to calculate vibration periods of five cantilever bars in forms of hollow conical barrels, with holes of various shape (Fig. 5). In each of these five cases, the generatrix of the external wall is a convex parabola and the external diameter is described by formula (2). The bars are made of plastic for which $\sqrt{\rho / E}=7 \cdot 10^{-4} \mathrm{~s} \cdot \mathrm{m}^{-1}$, they have the length $L=1.92 \mathrm{~m}$, the external diameter by the base $D=0.08 \mathrm{~m}$ and by the free end $d=0.06 \mathrm{~m}$ as well as the internal diameter by the base $D_{0}=0.05 \mathrm{~m}$. The following cases have been considered: 
a) the internal generatrix is a convex parabola, the smaller internal diameter is equal to $d_{0}=0.04 \mathrm{~m}$;

b) the internal generatrix is a straight line (the hole has the form of a truncated cone), the smaller internal diameter is equal to $d_{0}=0.04 \mathrm{~m}$;

c) the hole is a curvilinear cone, the wall thickness (measured perpendicularly to the bar axis) is constant and equal to $g=0.015 \mathrm{~m}$ what corresponds to the smaller internal diameter $d_{0}=0.03 \mathrm{~m}$;

d) the hole is a curvilinear cone, the wall thickness (measured perpendicularly to the bar axis) changes linearly from $g=0.015 \mathrm{~m}$ by the base to $g=0.010 \mathrm{~m}$ by the free end what corresponds to the smaller internal diameter $d_{0}=0.04 \mathrm{~m}$

e) the hole is a cylinder with the diameter $D_{0}=d_{0}=0.05 \mathrm{~m}$.
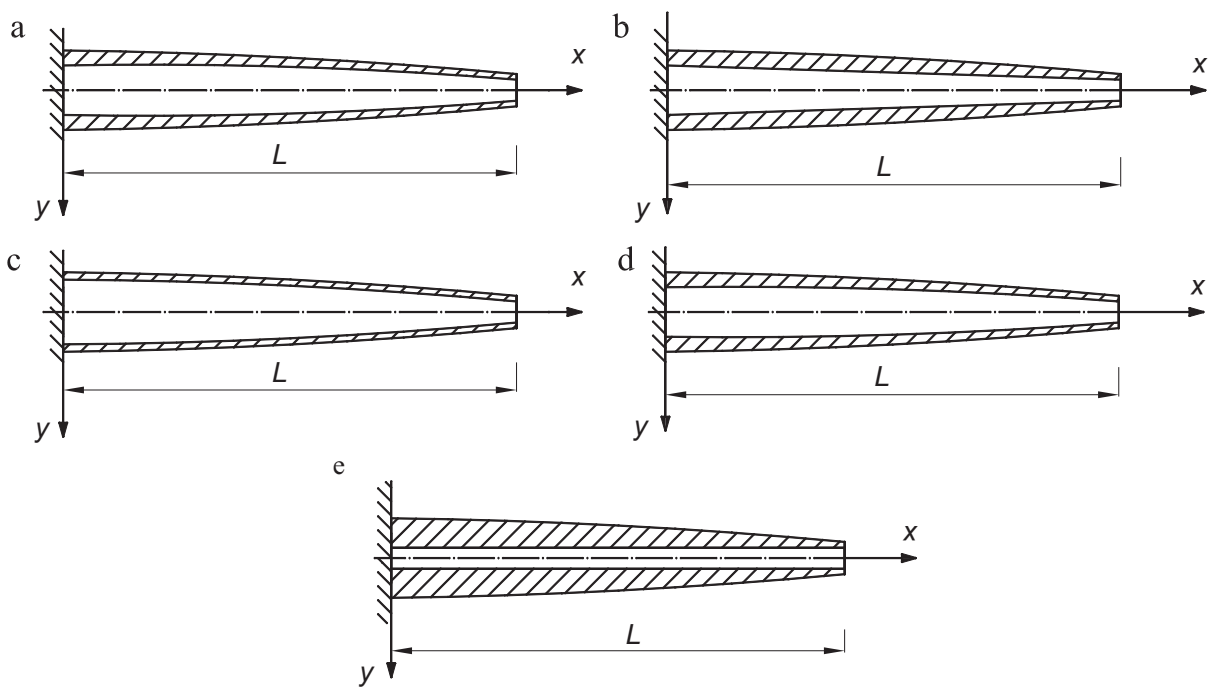

Fig. 5. Hollow conical barrel: (a) with the generatrix in the form of a convex parabola; (b) with the hole in the form of a truncated cone; (c) with a constant wall thickness; (d) with a linearly changing wall thickness; (e) with the cylindrical hole

The vibration period for the case "a", corresponding to the first frequency of free transverse vibrations, has been calculated from formula (21). Following the approach for a hollow cone barrel, the vibration periods for the four remaining solids of revolution have been determined. For the case " $b$ ", the internal diameter is described as

$$
\delta(x)=D_{0}-\left(D_{0}-d_{0}\right) \frac{x}{L}=D_{0}(1-b L x)
$$

For the case "c", the internal diameter can be expressed by the dependence

$$
\delta(x)=\Delta(x)-2 g=D\left(\alpha-a x^{2}\right)
$$

where $g$-wall thickness.

For the case "d", the internal diameter is a function of the wall thickness

$$
\delta(x)=\Delta(x)-2 g(x)
$$


and the wall thickness depends on the coordinate $x$ and can be expressed as

$$
g(x)=\frac{D-D_{0}}{2}-\left(\frac{D-D_{0}}{2}-\frac{d-d_{0}}{2}\right) \frac{x}{L}=\frac{D}{2}\left\{(1-\alpha)-\left[(1-\alpha)-\frac{\mu-\alpha \eta}{\mu \eta}\right] \frac{x}{L}\right\}
$$

For the case "e", the internal diameter has the constant value: $D_{0}=\alpha D=$ const.

The results of calculations of the vibration periods corresponding to the first natural frequency are as follows: for the case "a" $T=0.1636 \mathrm{~s}$, for "b" $T=0.1656 \mathrm{~s}$, for "c" $T=0.1673 \mathrm{~s}$, for "d" $T=0.1903 \mathrm{~s}$ and for "e" $T=0.1431 \mathrm{~s}$.

The lowest value of the vibration period for the hollow conical barrels under consideration characterizes the case "e", where the hole is cylindrical. The highest value of the period is obtained for the case "d", where the wall thickness is linearly changing. For the remaining cases, the values of the vibration periods are very close to each other.

\section{SUMMARY AND CONCLUSIONS}

The Rayleigh's method can be successfully applied for calculations of the first frequency of free (transverse) vibrations of non-prismatic cantilever bars with solid and hollow cross-section. The condition is that the external and internal diameters of the bar having the shape of a solid of revolution should give the possibility to be expressed in the form of a continuous and smooth function of the coordinate $x$. In some cases (for example, for a truncated cone bar), a solution is obtained in the form of elementary functions, in others - the numerical integration is inevitable. Then it is convenient to perform the calculations using a computer program, as e.g. Mathematica.

The examples 1 and 2 show that if the formulas (13) and (21) for vibration periods of the cantilever posts in the form of solids of revolution whose generatrices are parabolas (solid and hollow cone barrel), are derived such as in this paper - using the Rayleigh's method with assumption that the bar axis deflected during vibrations has a shape of a beam deflected by a static constant continuous load - then the results present high concordance with the FEM solution. The accuracy is the higher the higher is the slenderness of a bar.

It must be emphasized that the derived formula (21) is not valid in special cases: for a cone if $d=0$ and $d_{0}=0$, when $\frac{D_{0}}{D}=\frac{d_{0}}{d}$, as well as for a tube when $d=D$ and $d_{0}=D_{0}$. The results for those cases can be obtained by interpolation or valid dependences can be derived. It is also noteworthy that the derived formulas concern also the range $d>D$ and $d_{0}>D_{0}$ (not considered in this paper), i.e. when posts have the form of club or chalice.

\section{Acknowledgements}

The authors would like to express their sincere thanks to Jan Grudziński, Ph.D. Eng., for his help in the FEM calculations in the ANSYS.

\section{REFERENCES}

Abdelghany, S. M., Ewis, K. M., Mahmoud, A. A. \& Nassar, M. M. (2015). Vibration of a circular beam with variable cross sections using differential transformation method. Beni-Suef University Journal of Basic and Applied Sciences, 4 (3), 185-191. doi: 10.1016/j.bjbas.2015.05.006. 
Szlachetka, O., Jaworski, J., Chalecki, M. (2017). Analysis of free vibrations of cantilever bars with parabolically variable cross-sections using the Rayleigh's method. Acta Sci. Pol. Architectura, 16 (4), 5-14. doi: 10.22630/ASPA.2017.16.4.01.

Caruntu, D. I. (2007). Classical Jacobi polynomials, closed-form solutions for transverse vibrations. Journal of Sound and Vibration, 306 (3), 467-494. doi: 10.1016/j.jsv.2007.05.046.

Caruntu, D. I. (2009). Dynamic modal characteristics of transverse vibrations of cantilevers of parabolic thickness. Mechanics Research Communications, 36 (3), 391-404. doi: 10.1016/j.mechrescom.2008.07.005.

Conway, H. D. \& Dubil, J. F. (1965). Vibration frequencies of truncated-cone and wedge beams. Journal of Applied Mechanics, 32 (4), 932-934. doi: 10.1115/1.3627338.

Coşkun, S. B., Atay, M. T. \& Öztürk, B. (2011). Transverse vibration analysis of Euler-Bernoulli beams using analytical approximate techniques. INTECH Open Access Publisher. Retrieved from http://cdn.intechopen.com/pdfs-wm/14650.pdf.

Datta, A. K. \& Sil, S. N. (1996). An analysis of free undamped vibration of beams of varying cross-section. Computers \& Structures, 59 (3), 479-483. doi: 10.1016/0045-7949(95)60270-4.

Ece, M. C., Aydogdu, M. \& Taskin, V. (2007). Vibration of variable cross-section beam. Mechanics Research Communications, 34 (1), 78-84. doi: 10.1016/j.mechrescom.2006.06.005.

Jaworski, J., Szlachetka, O. \& Aguilera-Cortés, L.A. (2015). Zastosowanie metody Rayleigh'a do obliczenia pierwszej częstości drgań własnych słupów wspornikowych o zmiennym przekroju poprzecznym. Journal of Civil Engineering, Environment and Architecture, 62, 3/2, 185-194. doi: 10.7862/rb.2015.149.

Jaworski J. \& Szlachetka, O. (2015). Free vibration of cantilever beams of various cross-section. Dynamical systems. In J. Awrejcewicz et al. (Eds), Mechatronics and Life Sciences. DSTA'2015 (pp. 237-248). Lodz: Department of Automation, Biomechanics and Mechatronics.

Jaworski, J. \& Szlachetka, O. (2017). Free vibrations of cantilever bars with linear and nonlinear variable cross-section. Discontinuity, Nonlinearity, and Complexity, 6 (4), 489-501. doi: 10.5890/DNC.2017.12.007.

Kang, J. H. \& Leissa, A. W. (2004). Three-dimensional vibrations of solid cones with and without an axial circular cylindrical hole. International Journal of Solids And Structures, 41 (14), 3735-3746. doi: 10.3233/SAV-2012-0676.

Lau, J. H. (1984). Vibration frequencies for a non-uniform beam with end mass. Journal of Sound and Vibration, 97 (3), 513-521. doi: 10.1016/0022-460X(84)90276-1.

Naguleswaran, S. (1994). A direct solution for the transverse vibration of Euler-Bernoulli wedge and cone beams. Journal of Sound and Vibration, 172 (3), 289-304. doi: 10.1006/jsvi.1994.1176.

Wu, J. S. \& Chiang, L. K. (2004). Free vibrations of solid and hollow wedge beams with rectangular or circular cross-sections and carrying any number of point masses. International Journal for Numerical Methods in Engineering, 60 (3), 695-718. doi: 10.1002/nme.981.

Zhou, D. \& Cheung, Y. K. (2000). The free vibration of a type of tapered beams. Computer Methods in Applied Mechanics and Engineering, 188 (1), 203-216. doi: 10.1016/S0045-7825(99)00148-6.

\section{ANALIZA DRGAŃ WŁASNYCH PRĘTÓW WSPORNIKOWYCH O PARABOLICZNIE ZMIENNYCH PRZEKROJACH POPRZECZNYCH PRZY WYKORZYSTANIU METODY RAYLEIGH'A}

\section{STRESZCZENIE}

Metodą Rayleigh’a można wyznaczyć pierwszą częstość drgań własnych prętów (belek lub słupów) o zmiennym przekroju poprzecznym. Autorzy analizowali smukłe pręty z materiału sprężystego, które mają kształt bryły obrotowej: krzywoliniowego ściętego stożka oraz krzywoliniowej rury stożkowej. Przyjęto, że oś pręta odkształcona podczas drgań swobodnych ma kształt ugięcia statycznego pod stałym obciążeniem ciągłym. W pracy zastosowano metodę Rayleigh'a do wyznaczenia pierwszej częstości drgań własnych giętnych słupów wspornikowych w kształcie pełnego i wydrążonego krzywoliniowego ściętego stożka, którego tworząca jest parabolą wypukłą w stosunku do osi stożka. Wyniki obliczeń są bardzo bliskie rezultatom otrzymanym przy zastosowaniu metody elementów skończonych (MES).

Słowa kluczowe: pręt wspornikowy, zmienny przekrój, pierwsza częstość drgań własnych, metoda Rayleigh'a 